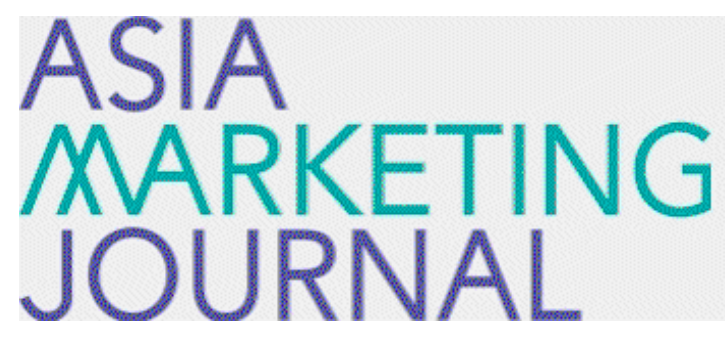

ASIA MARKETING JOURNAL

Volume 15 | Issue 3

Article 5

$10-30-2013$

\title{
Technology Licensing Agreements from an Organizational Learning Perspective
}

Jong Kuk Lee

Sang Young Song

Follow this and additional works at: https://amj.kma.re.kr/journal

Part of the Marketing Commons

\section{Recommended Citation}

Lee, Jong Kuk and Song, Sang Young (2013) "Technology Licensing Agreements from an Organizational Learning Perspective," Asia Marketing Journal: Vol. 15 : Iss. 3 , Article 5.

Available at: https://doi.org/10.53728/2765-6500.1559

This Article is brought to you for free and open access by Asia Marketing Journal. It has been accepted for inclusion in Asia Marketing Journal by an authorized editor of Asia Marketing Journal. 


\title{
Technology Licensing Agreements from an Organizational Learning Perspective*
}

\author{
Jongkuk Lee** \\ Sangyoung Song***
}

New product innovation is a process of embodying new knowledge in a product and technology licensing is getting popular as a means to innovations and introduction of new product to the market in today's competitive global market environment. Incumbents often rely on technology licensing to access new product opportunities created by other firms. Prior research has examined various aspects of technology licensing agreements such as specific contract terms of licensing agreements, e.g., distribution of control rights, exclusivity of licensing agreements, cross-licensing, and the scope of licensing agreements.

This study aims to provide answers to an important, but under-researched question: why do some incumbents initiate more licensing agreement for exploratory learning while others do it for exploitative learning along the innovation process?

We attempt to extend our knowledge of licensing agreements from an organizational learning perspective. Technology licensing as a specific form of interfirm linkages can be initiated with different learning objectives along the process of new product innovation. The exploratory stages of the innovation process such as discovery or research stages involve extensive searches to create new knowledge or capabilities, whereas the exploitative stages of the innovation process such as application or test stages near the commercialization are more focused on developing specific applications or improving their efficiency or reliability. Thus, different stages of the innovation process generate different types of learning and the resulting technological resources. We examine when incumbents as licensees initiate more licensing agreements for exploratory learning objectives and when more for exploitative learning objectives, focusing on two factors that may influence a firm's formation of exploratory and exploitative licensing agreements: 1) its past radical and incremental innovation experience and 2) its internal investments in R\&D and marketing. We develop and test our hypotheses regarding the relationship between a firm's radical and incremental new product experience, R\&D investment

* This work was supported by the National Research Foundation of Korea Grant funded by the Korean Government (NRF-2011-332-B00154)

** Assistant Professor of Marketing, Ewha School of Business, Ewha Womans University (jongkuk@ewha.ac.kr)

*** Associate Professor of Marketing. Ewha School of Business, Ewha Womans University, corresponding author (songs@ewha.ac.kr) 
intensity and marketing investment intensity, and the likelihood of engaging in exploratory and exploitive licensing agreements.

Using data collected from various secondary sources (Recap database, Compustat database, and FDA website), we analyzed technology licensing agreements initiated in the biotechnology and pharmaceutical industries from 1988 to 2011. The results of this study show that incumbents initiate exploratory rather than exploitative licensing agreements when they have more radical innovation experience and when they invest in R\&D activities more intensively; in contrast, they initiate exploitative rather than exploratory licensing agreements when they have more incremental innovation experience and when they invest in marketing activities more intensively.

The findings of this study contribute to the licensing and interfirm cooperation studies. First, this study lays a foundation to understand the organizational learning aspect of technology licensing agreements. Second, this study sheds lights on how a firm's internal investments in R\&D and marketing are linked to its tendency to initiate licensing agreements along the innovation process. Finally, the findings of this study provide important insight to managers regarding which technologies to gain via licensing agreements. This study suggests that firms need to consider their internal investments in $R \& D$ and marketing as well as their past innovation experiences when they initiate licensing agreements along the process of new product innovation.

Key words: exploratory technology licensing, exploitative technology licensing, past innovation experience, R\&D investment, marketing investment.

\section{Introduction}

In today's competitive global market environment, firms are under ever increasing pressure to innovate and introduce new products (Hauser, Tellis, and Griffin 2006). Incumbents often rely on technology licensing to access new product opportunities created by other firms (Boyd and Spekman 2010). Prior research has examined various aspects of technology licensing agreements. First, prior research has examined specific contract terms of licensing agreements, such as the distribution of control rights, exclusivity of licensing agreements, cross-licensing, or the scope of licensing agreements (e.g., Anand and Khanna 2000: Bessy and Brousseau 1998: Boyd and Brown 2012: Somaya, Kim, and Vonortas 2010). For instance, Boyd and Brown (2012) have analyzed the choice of marketing control rights associated with technology licensing from the real options perspective. Second, prior research also has investigated the rate of technology licensing agreements (Fosfuri 2006) as well as the incentives for firms to enter into technology licensing such as patents protection or the 
presence of complementary assets (Arora and Ceccagnoli 2006).

Initiating ties with other firms is an important route to organizational learning (Koza and Lewin 1998). However, little is known about technology licensing from an organizational learning perspective. Technology licensing as a specific form of interfirm linkages can be initiated with different learning objectives along the process of new product innovation. In this study, we attempt to extend our knowledge of licensing agreements from an organizational learning perspective. Organizational learning is "a process through which organizations attend to and adapt to their external environments" (Baum, $\mathrm{Li}$, and Usher 2000). Prior research has distinguished between exploratory and exploitative learning for which firms initiate cooperative relationships with other firms (Koza and Lewin 1998: Rothaermel and Deeds 2004). Exploitative learning refers to learning through local searches, experiential refinement, and selection of existing routines, whereas exploratory learning refers to learning through the processes of concerted variation, planned experimentation, and play (Baum, Li, and Usher 2000: March 1991).

We examine when incumbents as licensees initiate more licensing agreements for exploratory learning objectives and when more for exploitative learning objectives. We focus on two factors that may influence a firm's tendency to initiate exploratory and exploitative licensing agreements: 1) its past radical and incremental innovation experience and 2) its internal investments in $R \& D$ and marketing.

With data collected from various secondary sources (Recap database, Compustat database, and FDA website), we analyzed technology licensing agreements initiated in the biotechnology and pharmaceutical industries from 1988 to 2011. The results of this study show that incumbents initiate exploratory rather than exploitative licensing agreements when they have more radical innovation experience and when they invest in R\&D activities more intensively; in contrast, they initiate exploitative rather than exploratory licensing agreements when they have more incremental innovation experience and when they invest in marketing activities more intensively.

The findings of this study contribute to the licensing and interfirm cooperation studies. First, this study lays a foundation to understand the organizational learning aspect of technology licensing agreements. Second, this study sheds lights on how a firm's internal investments in $\mathrm{R} \& \mathrm{D}$ and marketing are linked to its tendency to initiate licensing agreements along the innovation process. Finally, the findings of this study provide important insight to managers regarding which technologies to gain via licensing agreements. This study suggests that firms need to consider their internal investments in R\&D and marketing as well as their past innovation experiences when they initiate licensing agreements along the process of new product innovation. 


\section{Technology licensing agreements as learning mechanisms}

New product innovation is a process of embodying new knowledge in a product (Madhavan and Grover 1998). From an organizational learning perspective, new product innovation is achieved through exploratory and exploitative learning along the innovation process (Koza and Lewin 1998). The exploratory stages of the innovation process such as discovery or research stages involve extensive searches to create new knowledge or capabilities, whereas the exploitative stages of the innovation process such as application or test stages near the commercialization are more focused on developing specific applications or improving their efficiency or reliability (Rothaermel and Deeds 2004). From the technological aspect, such exploratory efforts at the early stages of the innovation process pursue a shift to a different technological trajectory. whereas exploitative efforts at the late stages focuses on improving existing technological components by building on the existing technological trajectory (Benner and Tushman 2002). Thus, different stages of the innovation process generate different types of learning and the resulting technological resources. Technology licensing to gain external knowledge can be initiated with these different learning objectives. It can target more exploratory learning, i.e., basic research or exploration of new technologies, or more exploitative learning, i.e., applied projects with immediate goals or projects for improving current technologies or products (Jap 2001). We define exploratory licensing as an agreement to license technologies that are at the exploratory stages of the innovation process: exploitative licensing as an agreement to li-

〈Figure 1〉 Conceptual Model

Past innovation experience

- Radical new product experience

- Incremental new product experience

Internal investments
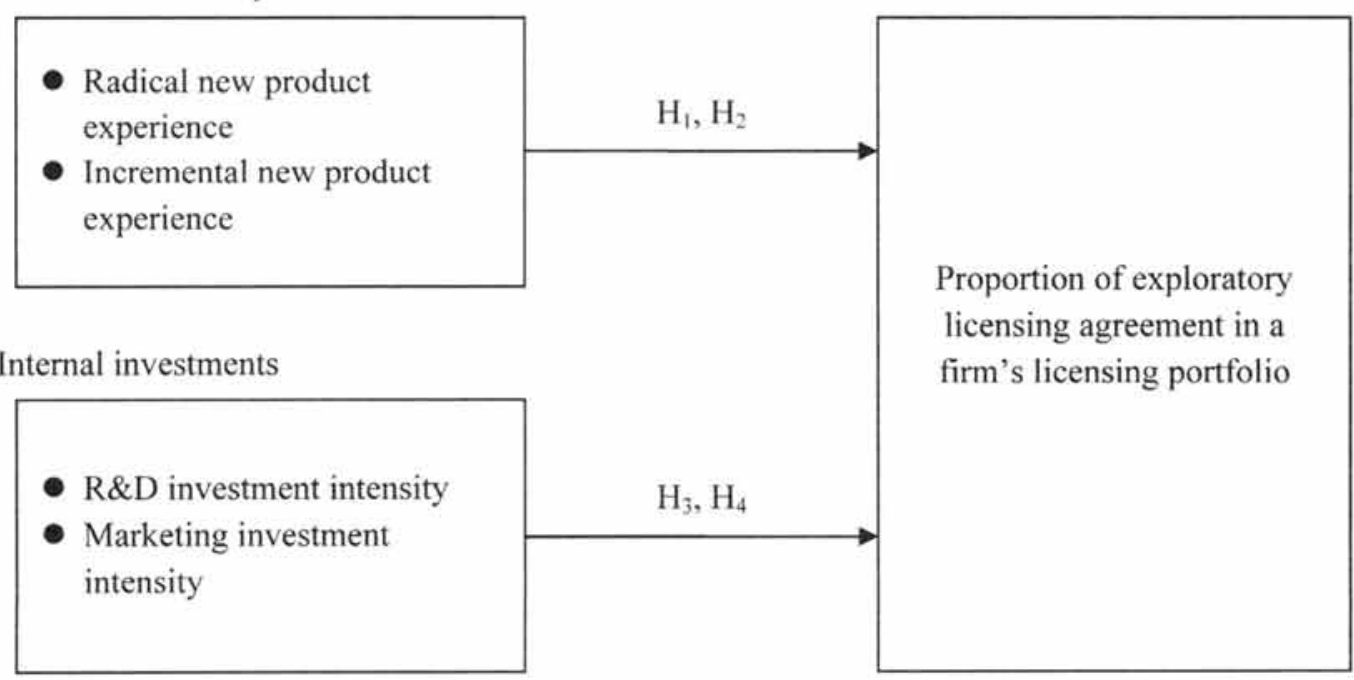
cense technologies that are at the exploitative stages.

We examine when incumbents as licensees initiate more licensing agreements for exploratory objectives and when for exploitative objectives. In particular, we focus on two factors that may influence a firm's formation of exploratory and exploitative licensing agreements: 1) its internal investments in $\mathrm{R} \& \mathrm{D}$ or marketing and 2) past radical and incremental innovation experience. Figure 1 summarizes the conceptual model of this study.

\section{Hypotheses}

\subsection{Past innovation experience}

We examine the types of new products that incumbents have introduced previously as the primary factors that drive incumbents to initiate technology licensing agreements with different learning objectives. For the types of new products, we distinguish between radical and incremental new products (Sorescu, Chandy, and Prabhu 2003: Sorescu and Spanjol 2008: Wuyts, Dutta, and Stremersch 2004). Radical new products are defined as new products that involve a fundamental technological breakthrough and that provide the market potential to substantially increase in customer value compared with current products in the market
(Chandy and Tellis 1998), whereas incremental new products are defined as new products that do not meet one or both of these requirements (Wuyts, Dutta, and Stremersch 2004).

\subsubsection{Radical new product experience.}

Incumbents that have introduced a greater number of radical new products to the market in the past will have a greater tendency to initiate exploratory technology licensing agreements. First, given the path dependence of innovation activities (Gatignon and Xuereb 1997: Slater, Olson, and Hult 2006), these incumbents will have a greater need for exploratory learning to continue to introduce radical new products in the market. Even though firms can accumulate technological capability through past radical innovation activities, firms in the high-tech industries face rapid, unpredictable technological advances along with high technological uncertainty (Powell, Koput, and Smith-Doerr 1996). Therefore, firms that pursue more exploratory learning will exhibit a tendency toward enforcing their exploratory learning behavior under rapid and unpredictable technological changes in the high-tech industries.

Initiating more licensing agreements at the early rather than late stages will provide more opportunities to access diverse technological resources that can lead to radical new products. For instance, new compounds or materials $\mathrm{ex}^{-}$ plored at the discovery or research stages tend 
to determine the potential value of projects to generate radical new products in the biotech and pharmaceutical industries (Lee 2011).

Second, firms that introduce radical new products will be more tolerant to the failure risks of projects at the early stages of the innovation process. On average, they will better accept the high technological uncertainty in the pursuit of more fundamental breakthroughs. For instance, radical new products compared with incremental new products generate substantial profits over the long-term period and can compensate for the losses in most other projects that turned out to be failure in the innovation process or in the market (Sorescu, Chandy, and Prabhu 2003). Thus, expecting such potential value of successful radical new products, incumbents that introduced radical new products in the past will be more willing to initiate exploratory technology licensing agreements at the early stages of the innovation process in searching for radical new product opportunities at the cost of high technological uncertainty associated with exploratory learning.

$H_{1}$ : The greater a firm's radical new product experience, the greater will be the proportion of exploratory licensing agreements in its technology licensing portfolio.

\subsubsection{Incremental new product experience}

In contrast, incumbents that have more in- cremental new product experience in the past will have a greater tendency to initiate technology licensing agreements for exploitative learning. First, incumbents will have more opportunities for projects that can lead to incremental new products by forming licensing agreements at the exploitative rather than exploratory stages of the innovation process. The late stages of the innovation process near the commercialization involve more exploitative searches to appropriate the current stocks of knowledge or capabilities, which likely lead to more incremental innovations (McNamara and Baden-Fuller 2007). Second, efficiency becomes more critical for incumbents that focus on incremental new products, given the relative short duration of marginally improved products (Wuyts, Dutta, and Stremersch 2004). Namely, the speed of new product introduction provides a significant competitive advantage in the market for incremental new products. Firms that have introduced incremental new products in past will have stronger needs to avoid technological uncertainties and introduce new products more frequently to maintain its competitive advantage in the market. Therefore, incremental new product experience will motivate incumbents to form exploratory rather than exploitative technology licensing agreements.

$\mathrm{H}_{2}$ : The greater a firm's incremental new product experience, the lower will be the proportion of exploratory licensing agreements in 
its technology licensing portfolio.

\subsection{Internal investments in $R \& D$ and marketing}

\subsubsection{R\&D investment.}

A firm's intensity of R\&D investments reflects its strategic orientation towards exploratory learning. Through R\&D investments, firms explore new technological opportunities to introduce new products or process. Firms rely on R\&D activities to build technological capability to serve the needs of customers (Gatignon and Xuereb 1997). R\&D investments have been emphasized as a key mechanism to create value for customers (Mizik and Jacobson 2003, Lee 2010). As such, a firm's R\&D investment intensity indicates its emphasis on exploratory learning for value creation. Further, R\&D investments also serve as a capability to evaluate and select innovative firms of high potential at the early stages of the innovation process. A firm accumulates its absorptive capacity through internal investments in R\&D activities (Cohen and Levinthal 1990). The exploratory stages of the innovation process involve a high level of technological uncertainty. A firm of high technological capability will be more effective at the exploratory learning through technology licensing. Therefore, a firm exhibiting greater $R \& D$ investment intensity will be more committed to exploratory licensing.
$H_{3}$ : The greater a firm's $R \& D$ investment intensity, the higher will be the proportion of exploratory licensing agreements in its technology licensing portfolio.

\subsubsection{Marketing investment.}

Incumbents that invest more in marketing activities reflect its strategic focus on exploitative learning rather than pursuing fundamental breakthroughs (Mizik and Jacobson 2003). They are more focused on value appropriation at the later stages of the innovation process. Marketing capability, which refers to a firm's expertise in developing and implementing sales, distribution, and promotion strategies (Boyd and Brown 2012), is a critical factor to successfully commercialize new technologies or products (Dutta, Narasimhan, and Rajiv 1999). A firm focused on marketing investments will be motivated to initiate more licensing agreements at the exploitative stages to leverage its internal marketing capabilities, rather than taking the technological uncertainty in the exploratory stages of the innovation process. Further, incumbents with a focus on marketing activities may lack the capacity to absorb technological resources from the exploratory stages of the innovation process. Therefore, a firm investing in marketing more intensively will be more committed to exploitative licensing.

$H_{1}$ : The greater a firm's marketing invest- 
ment intensity, the lower will be the proportion of exploratory licensing agreements in its technology licensing portfolio.

\section{Methodology}

\subsection{Context and data collection}

We tested our hypotheses with technology licensing agreements initiated by firms in the biotech and pharmaceutical industries. This industrial context has been commonly used in the previous studies of interfirm collaboration (Hoang and Rothaermel 2010: Wuyts, Dutta, and Stremersch 2004). The rapid advances of bio-technologies in the last several decades have led incumbents to initiate external linkages including licensing agreements with innovative firms to introduce new products and maintain their competitive advantage (Stremersch and Dyck 2009).

We relied on the diverse data sources to measure the variables of interest. First of all, we collected licensing data from Recap database. This database provides comprehensive information about interfirm collaboration including licensing activities that occur in the biotech and pharmaceutical industries (Filson and Morales 2006: Hoang and Rothaermel 2010). We collected innovation information of incumbents from FDA website (Sorescu, Chandy, and
Prabhu 2003). Finally, we relied on Compustat database to measure a firm's investment in $R \& D$ and marketing as well as other financial information that may influence technology licensing along the innovation process. Firms in our sample consist only the publicly traded firms on the New York, American, and Nasdaq stock exchanges. From these secondary data sources, we collected data needed for this study from 1988 to 2011. After eliminating sample with missing values, 88 firms were remained from this study. We calculated the annual licensing portfolio for these focal firms. After accounting for firms engaged in licensing agreements in multiple years, we had an unbalanced panel dataset composed of 204 observations of 88 firms.

\subsection{Variables}

\subsubsection{The proportion of exploratory licensing}

Consistent with prior research (Rothaermel and Deeds 2004), we classified technology licensing agreements formed prior to clinical test stages in the new drug development process as exploratory licensing. In contrast, licensing agreements at the later stages such as clinical tests or approval stages were treated as exploitative ones (McNamara and Baden-Fuller 2007). To calculate the proportion of exploratory licensing agreements in a firm's technology licensing portfolio, we divided the number of 
its exploratory licensing agreements by the total number of licensing agreements that a firm initiated in a given year.

\subsubsection{Radical innovation experience}

We measured radical innovation experience by the number of radical new drugs approved by FDA in the past five years. Following prior innovation literature in the pharmaceutical industries (Sorescu, Chandy, and Prabhu 2003: Wuyts, Dutta, and Stremersch 2004), radical new drugs refer to those that applied new ingredients that have not been used previously and at the same time were classified as priority review drugs that provide a significant advance compared with the existing drugs. These new drugs reflect fundamental technological advances to accomplish significant advances in customer values.

\subsubsection{Incremental innovation experience}

We measured incremental innovation experience by the number of a firm's incremental new drugs approved by FDA in the past five years. Following prior innovation literature in the pharmaceutical industries (Sorescu, Chandy, and Prabhu 2003: Wuyts, Dutta, and Stremersch 2004), we operationalized incremental new drugs as new drugs that applied new ingredients that have been used previously or those that FDA classified as standard review drugs that pro- vide a similar level of benefits compared with the existing drugs. These new drugs reflect incremental technological changes and provide only marginal advances in customer values.

\subsubsection{R\&D/ marketing investment intensity}

We also test $\mathrm{R} \& \mathrm{D}$ and marketing investment intensity as explanatory variables. We measured $R \& D$ investment intensity by dividing a firm's R\&D expenses with its total assets (Dutta, Narasimhan, and Rajiv 1999: Mizik 2010). To measure marketing intensity, we divided a firm's marketing expenses by its total assets. Consistent with prior research (Mizik 2010), we derived marketing expenses from sales and general administrative expenses minus R\&D expenses. We also employed alternative measures of $R \& D$ investment intensity and marketing intensity using sales instead of total assets as the denominator.

\subsubsection{Control variables}

We also control for the effects of firm size which we measured by total assets, total number of licensing agreements, a dummy variable for bio-tech industry (SIC2836), cash flow, return on assets (ROA), industry dynamism, and year dummies. Cash flow is calculated as income before extraordinary items plus depreciation and amortization minus working capital accruals 
(Almeida, Campello, and Weisbach 2004). We used one-year lagged cash flow and ROA. Industry dynamism refers to the unpredictability of changes in overall market size in a given industry (Wang and Chen 2010). We first computed the standard deviation of sales in the R\&D firm's product industry (four-digit SIC code) across the prior five years, divided by the mean value of industry sales for those years.

\subsection{Empirical model}

Our dependent variable is a proportion of exploratory licensing in a firm's licensing portfolio and therefore bounded between 0 and 1 . Therefore, standard linear models are not appropriated since the predicted values of $\mathrm{de}^{-}$ pendent variable is not restricted between 0 and 1 (Wooldridge 2002). Papke and Wooldridge (1996) suggested a fractional probit regression. We used the fractional probit model to examine fractional development variables that are bounded between 0 and 1 . We also applied robust standard errors to take into account firmfixed effects (Rogers 1993).

\section{Results}

Table 1 presents descriptive statistics and correlations between variables. The mean var- iance inflation factor is 2.11 and the maximum variance inflation factor is 4.31, indicating no evidence of multicolinearity in our sample. Table 2 presents the estimation results. Model 1 included only control variables, Model 2 tested the effects of past innovation experience, Model 3 tested the effect of internal investments, and Model 4 present a full model by including all variables. All models show consistent results, indicating the robustness of our finding. Model 4 shows that radical innovation experience has a positive effect on the proportion of exploratory licensing in a firm's licensing portfolio ( $\beta=0.196, p=0.089)$, in support of Hypothesis 1 albeit the marginal statistical significance. These results indicate that a firm with more radical innovation in the past has a tendency to continue or even reinforce its radical innovations via more exploratory learning. However, we found no significant effect of incremental innovation experience on the proportion of exploratory licensing $(\beta=$ -0.040, n.s.), failing to support Hypothesis 2.

Model 4 further shows a positive effect of $R \& D$ investment intensity on the proportion of exploratory licensing ( $\beta=0.161, p=0.016$ ), in support of Hypothesis 3. In contrast, marketing investment intensity has a negative effect on the proportion of exploratory licensing $(\beta=$ $-0.684, p=0.014)$. This supports Hypothesis 4 . These findings indicate that a firm's licensing behaviors are contingent upon its internal investment behaviors. 


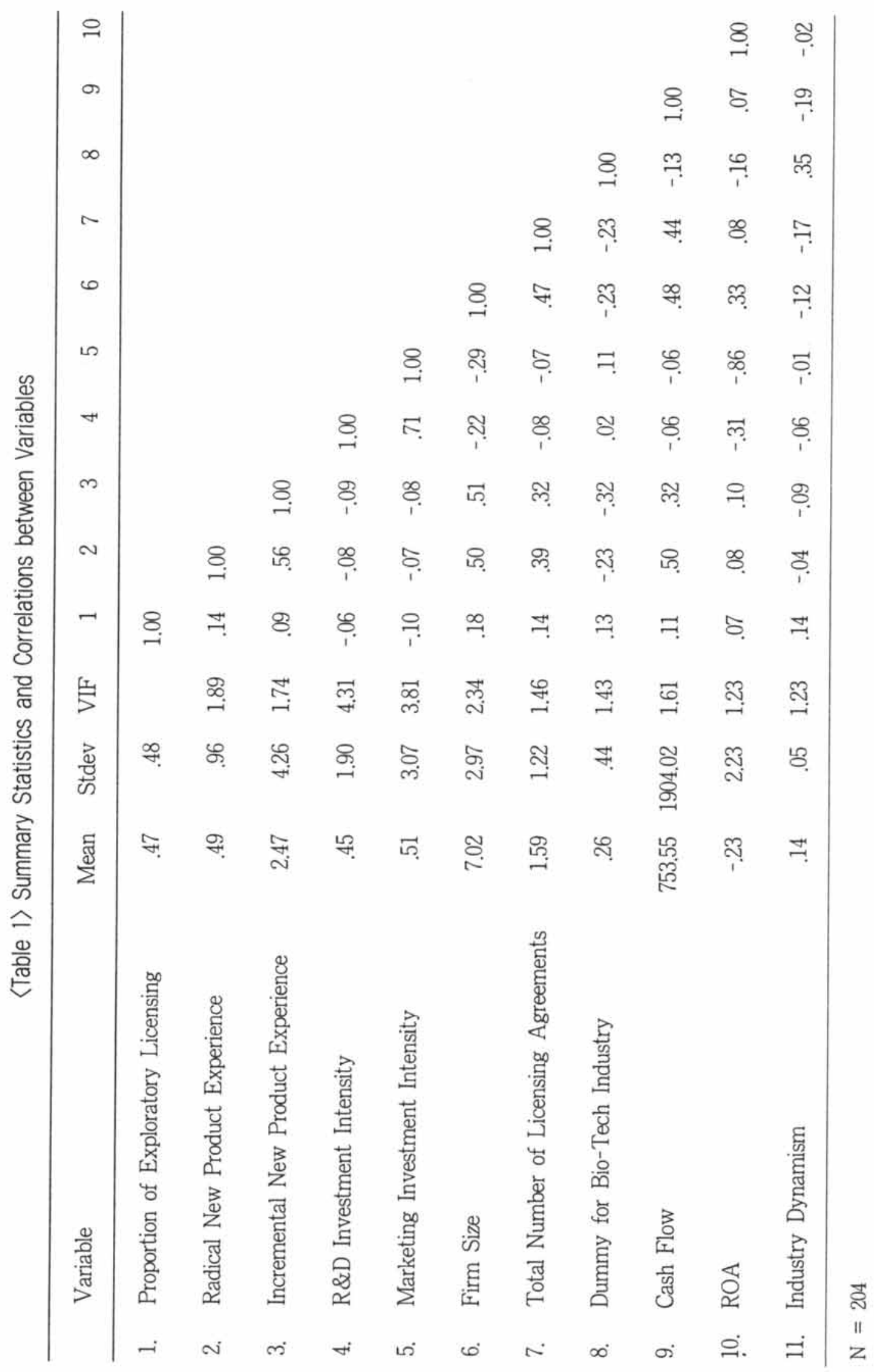




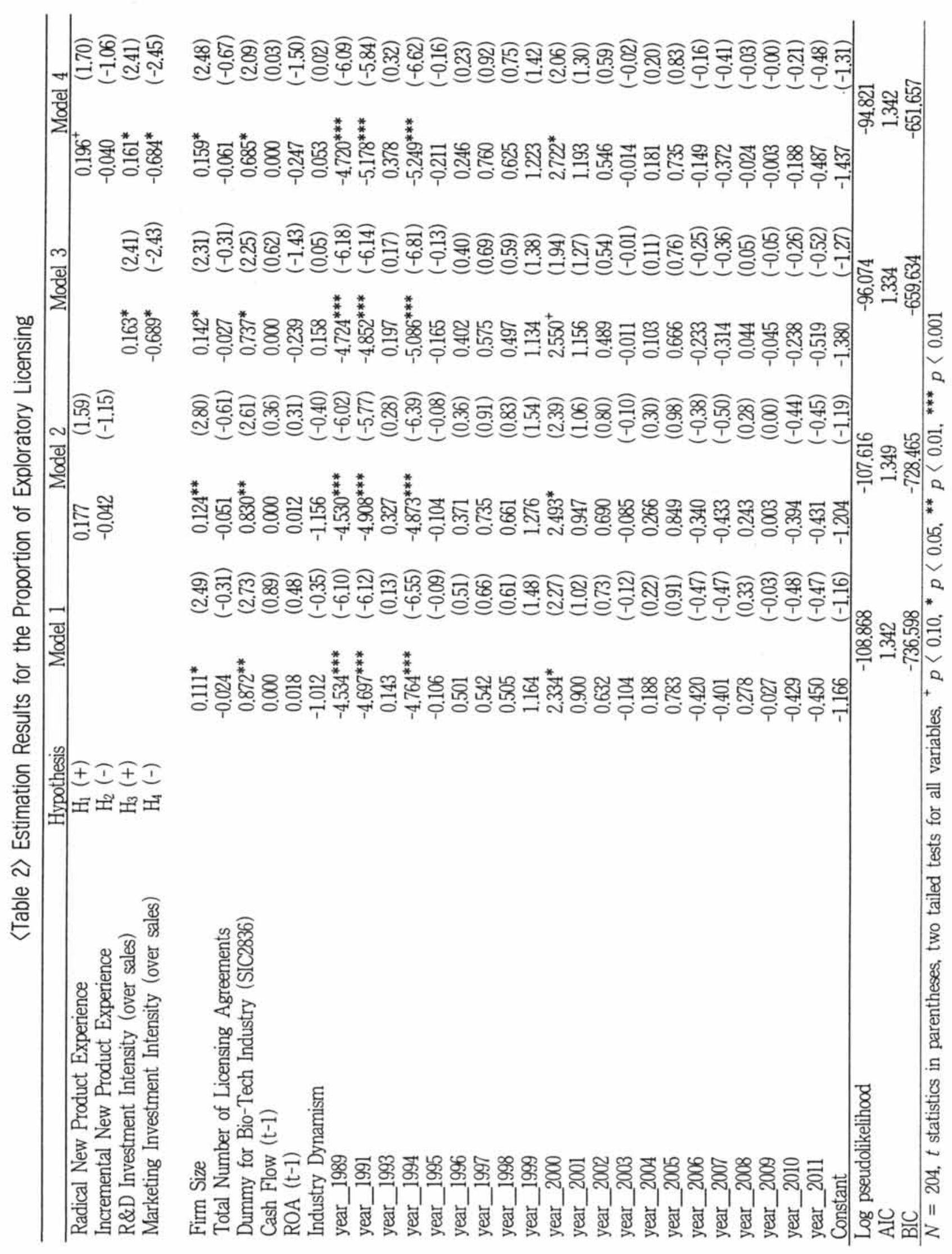


Regarding the effects of control variables, firm size has a positive effect on the proportion of exploratory licensing $(\beta=0.159, p<0.05)$. Biotechnology firms compared with pharmaceutical firms are engaged in exploratory licensing to a greater degree $(\beta=0.685, p<$ 0.01). The other control variables, i.e., licensing portfolio size, cash flow, return on assets, industry dynamism, have no statistically significant effects.

\section{Discussion}

Technology licensing is getting popular as a route to obtain technological and marketing resources (Boyd and Brown 2012). This study answers an important, but under researched question. Why do some incumbents initiate more licensing agreement for exploratory learning and why other incumbents for exploitative learning along the innovation process? The findings of this study provide new insights re- $^{-}$ garding technology licensing agreements.

\subsection{Theoretical and Managerial Implications}

First, this study lays a foundation to understand the organizational learning aspect of technology licensing agreements. This study applied organizational learning to technology li- censing formation. Organizational learning has been widely used as a foundation that underlies the initiation of external linkages for diverse activities along the value chain, such as technological collaboration, joint marketing efforts, or joint ventures (e.g., Hoang and Rothaermel 2010: McNamara and Baden-Fuller 2007; Rothaermel 2001: Rothaermel and Deeds 2004). We further extend this stream of research to licensing agreements that incumbents as licensees initiate with $R \& D$ firms. The findings of this study shows that an incumbent's past innovation experience significantly influences its tendency for technology licensing agreements along the innovation process. A firm that introduced more radical new products in the past has a tendency to initiate more exploratory licensing agreements targeting technologies that are at the early stages of the innovation process.

Second, this study sheds lights on how a firm's internal investments in $R \& D$ and marketing are linked to its tendency to initiate licensing agreements along the innovation process. A firm's behaviors in investing resources for $\mathrm{R} \& \mathrm{D}$ and marketing activities reflect its strategic orientation towards value creation and value appropriation (Mizik and Jacobson 2003). The findings of this study corroborate with previous studies that conceptualized R\&D from the value creation aspect and marketing from the value appropriation aspect (Mizik and Jacobson 2003: Teece 1986). A firm's greater 
investment in $R \& D$ reflects its tendency towards more exploratory learning for effective value creation, whereas its greater investment in marketing reflects its tendency towards more exploitative learning for effective value appropriation.

At the same time, through internal investments in the related tasks, firms develop the ability to "recognize the value of new, external information, assimilate it, and apply it to commercial ends" (Cohen and Levinthal 1990, p. 128). Expertise in R\&D through internal investments can serve as the ability for exploratory learning and thus can motivate exploratory licensing agreements at the early stages of the innovation process, whereas those with expertise in marketing can serve as the ability for exploitative learning and thus can motivate exploitative licensing agreements at the late stages of the innovation process.

Finally, the findings of this study provide important insight to managers regarding which technologies to gain via licensing agreements. Mangers initiating licensing agreements to gain externally developed technological resources face the choice between two types of technologies along the innovation process, i.e., exploratory technologies that are still at the early stages of the innovation process versus exploitative technologies that are at the late stages of the innovation process. This study shows that they need to consider their internal investments in R\&D and marketing as well as their past innovation experiences.

\subsection{Limitation and Future Research}

First, this study focused on the initiation of technology licensing agreements. Further research efforts are needed to investigate the firm performance impact of technology licensing agreements along the innovation process. In particular, exploratory and exploitative licensing agreements may influence firm performance in different ways. For instance, exploratory licensing agreements are expected to enhance firm performance by reinforcing value creation capability. In contrast, exploitative licensing agreements may influence firm performance through more effective value appropriation. Investing the firm performance impactions of these different types of licensing will provide a promising research opportunity.

Second, we focused on biotech and pharmaceutical industries as research context for this study. This study needs to be extended to more diverse industrial contexts. Technology licensing agreements in different industries may involve different types of concerns such as available licensing partners, knowledge leakage, or a specific form of opportunistic behaviors of partners. Future research can further develop our conceptual framework to incorporate more diverse factors that may influence the formation of exploratory and exploitative licensing agreements in various industrial contexts.

Finally, we focused on licensing agreements only rather than considering other type of in- 
terfirm collaboration such as alliances or joint ventures. Future research can examine how these different types of collaboration activities interact with each other in forming collaboration agreements.

〈Received July 1.2013〉

〈1st Revised August 13. 2013〉 〈2nd Revised September 4. 2013〉 〈Accepted September 10. 2013〉

\section{References}

Almeida, Heitor, Murillo Campello, and Michael Weisbach (2004), "The Cash Flow Sensitivity of Cash," Journal of Finance, 59, 1777-1804.

Anand, Bharat N. and Tarun Khanna (2000). "The Structure of Licensing Contracts," The Journal of Industrial Economics, 48 (1), 103-35.

Arora, Ashish and Marco Ceccagnoli (2006), "Patent Protection, Complementary Assets, and Firms? Incentives for Technology $\mathrm{Li}^{-}$ censing," Management Science, 52 (2), 293-308.

Baum, J. A. C., S. X. Li, and J. M. Usher (2000). "Making the Next Move: How Experiential and Vicarious Learning Shape the Locations of Chains' Acquisitions," Administrative Science Quarterly, 45 (4), 766-801.
Benner, M. J. and M. Tushman (2002), "Process Management and Technological Innovation: A Longitudinal Study of the Photography and Paint Industries," Administrative Science Quarterly, 47 (4), 676-706.

Bessy. Christian and Eric Brousseau (1998), "Technology Licensing Contracts Features and Diversity," International Review of Law and Economics, 18 (4), 451-89.

Boyd, D. Eric and BrianP Brown (2012), "Marketing Control Rights and Their Distribution within Technology Licensing Agreements:

A Real Options Perspective," Journal of the Academy of Marketing Science, 40 (5), 659-72.

Boyd, D. Eric and Robert E. Spekman (2010), "The Licensing of Market Development Rights within Technology Alliances: A Shareholder Value Perspective*." Journal of Product Innovation Management, 27 (4), 593-605.

Chandy, Rajesh K. and Gerard J. Tellis (1998), "Organizing for Radical Product Innovation: The Overlooked Role of Willingness to Cannibalize," Journal of Marketing Research, 35 (4), 474-87.

Cohen, Wesley M. and Daniel A. Levinthal (1990), "Absorptive Capacity: A New Perspective on Learning and Innovation," Administrative Science Quarterly, 35 (1), $128-52$.

Dutta, Shantanu, Om Narasimhan, and Surendra Rajiv (1999). "Success in High-Technology 
Markets: Is Marketing Capability Critical?" Marketing Science, 18 (4), 547-68.

Filson, Darren and Rosa Morales (2006), "Equity Links and Information Acquisition in Biotechnology Alliances," Journal of Economic Behavior \& Organization, 59 (1), 1-28.

Gatignon, Hubert and Jean-Marc Xuereb (1997), "Strategic Orientation of the Firm and New Product Performance," Journal of Marketing Research, 34 (1), 77-90.

Hauser, John, Gerard J. Tellis, and Abbie Griffin (2006), "Research on Innovation: A Review and Agenda for Marketing Science," Marketing Science, 25 (6), 687717.

Hoang, H. and F. T. Rothaermel (2010), "Leveraging Internal and External Experience: Exploration, Exploitation, and R\&D Project Performance," Strategic Management Journal, 31 (7), 734-58.

Jap, Sandy D. (2001), "'Pie Sharing” in Complex Collaboration Contexts," Journal of Marketing Research, 38 (February), 86-99.

Koza, Mitchell P. and Arie Y. Lewin (1998), "The Co-Evolution of Strategic Alliances," Organization Science, 9 (3), 255-64.

Lee, Jongkuk (2010), “The Effect of Customer Co-development on Firm Value," Asia Marketing Journal, 12 (3), 25-41.

Lee, Jongkuk (2011), “The Alignment of Contract Terms for Knowledge-Creating and Knowledge-Appropriating Relationship Port- folios," Journal of Marketing, 75 (4), 11027.

Madhavan, Ravindranath and Rajiv Grover (1998), "From Embedded Knowledge to Embodied Knowledge: New Product Development as Knowledge Management," Journal of Marketing, 62 (4), 1-12.

March, James G. (1991). "Exploration and Exploitation in Organizational Learning," Organization Science, 2 (1), 71-87.

McNamara, Peter and Charles Baden-Fuller (2007), "Shareholder Returns and the Exploration-Exploitation Dilemma: R\&D Announcements by Biotechnology Firms," Research Policy, 36, 548-65.

Mizik, Natalie (2010), “The Theory and Practice of Myopic Management," Journal of Marketing Research, 47 (4), 594.

Mizik, Natalie and Robert Jacobson (2003), "Trading Off between Value Creation and Value Appropriation: The Financial Implications of Shifts in Strategic Emphasis," Journal of Marketing, 67 (1), 63-76.

Papke, Leslie E. and Jeffrey Wooldridge (1996), "Econometric Methods for Fractional Response Variables with an Application to 401 (K) Plan Participation Rates," Journal of Applied Econometrics, 11, 619-32.

Powell, W. W., Koput, K. W.. \& Smith-Doerr, L. (1996). Interorganizational Collaboration and the Locus of Innovation: Networks of Learning in Biotechnology. Administrative Science Quarterly, 41(1), 116-145. 
Rogers, William (1993), "Regression Standard Errors in Clustered Samples," Stata Technical bulletin, 13, 19-23.

Rothaermel, Frank T. (2001), "Incumbent's Advantage through Exploiting Complementary Assets Via Interfirm Cooperation," Strategic Management Journal, 22 (6-7), 68799.

Rothaermel, Frank T. and David L. Deeds (2004), "Exploration and Exploitation Alliances in Biotechnology: A System of New Product Development," Strategic Management Journal, 25 (3), 201-21.

Slater, Stanley F., Eric M. Olson, and G. Tomas M. Hult (2006), "The Moderating Influence of Strategic Orientation on the Strategy Formation Capability - Performance Relationship," Strategic Management Journal, 27 (12), 1221-31.

Somaya, Deepak, Youngjun Kim, and Nicholas S. Vonortas (2010), "Exclusivity in Licensing Alliances: Using Hostages to Support Technology Commercialization," Strategic Management Journal, 32 (2), 159-86. Sorescu, Alina B., Rajesh K. Chandy, and Jaideep C. Prabhu (2003), “Sources and Financial Consequences of Radical Innovation: Insights from Pharmaceuticals," Journal of Marketing, 67 (October), 82-102.
Sorescu, Alina B. and Jelena Spanjol (2008), "Innovation's Effect on Firm Value and Risk: Insights from Consumer Packaged Goods," Journal of Marketing, 72 (2), 114-32.

Stremersch, Stefan and Walter Van Dyck (2009), "Marketing of the Life Sciences: A New Framework and Research Agenda for a Nascent Field," Journal of Marketing. 73 (4), 4-30.

Teece, David J. (1986), "Profiting from Technological Innovation: Implications for Integration, Collaboration, Licensing and Public Policy," Research Policy, 15 (6), 285-305. Wang, H., \& Chen, W.-R. (2010). Is firmspecific innovation associated with greater value appropriation? The roles of environmental dynamism and technological diversity. Research Policy, 39(1), 141-154.

Wooldridge, J. (2002), Econometric Analysis of Cross Section and Panel Data, Cambridge, MA: MIT Press.

Wuyts, Stefan, Shantanu Dutta, and Stefan Stremersch (2004), "Portfolios of Interfirm Agreements in Technology-Intensive Markets: Consequences for Innovation and Profitability," Journal of Marketing, 68 (2), 88-100. 